\title{
Relation between the Psychological Pain and Alexithymia among Palestinian University Students
}

\author{
Omar Taleb Rimawi \\ Associate Professor, Department of Psychology \\ Al-Quds University \\ ORCID.0000-0002-9376-3917 \\ Ibrahim Suleiman Almasri \\ Assistant Professor, Department of Psychology \\ Hebron University \\ ORCID. 0000-0003-1288-1098
}

\begin{abstract}
Purpose: The current study aimed at identifying the relation between the psychological pain and Alexithymia among Palestinian university students. The study tool was applied to a sample of Hebron and Al-Quds universities students. The sample included (500) male and female students, from the first semester of the academic year 2019 randomly selected. The results: of the study showed a positive relationship between Alexithymia and psychological pain, and there are significant differences in the level of Alexithymia among Palestinian university students due to the university that favored Hebron University students, and for the gender in favor of males and for the college that favored the scientific college students.
\end{abstract}

Key words: Psychological pain, Alexithymia, Palestinian universities students.

\section{Introduction}

Alexithymia is a psychological concept that indicates the existence of difficulties in the person's determination and expression of his own feeling. it is the inability to identify, express or describe one's feelings. Many people in society suffer from mental disorders pertaining to this feature, because people with Alexithymia may suffer emotionally, psychologically or physically as a result of this cognitive deficit (Baum, A., \& Grunberg, 1991; Besharat, Rostami, Pourhossein, \& Mirzamani, 2006). Psychoanalysts are among those who perceived their patients with mental illnesses, when they faced great difficulties in the expression of their emotions in a verbal manner, and that these people lack symbolic representations (Brahmiya, 2016). The results of previous studies (Eastabrook,2008; Eid, \& Boucher,2012; Sherbiny, 2012) confirm that individuals suffering from Alexithymia lack the ability to determine the meaning of exciting verbal and non-verbal emotions as facial expressions, and they find difficulty to anticipate the people's feelings in different situations.The American Psychiatric Association (APA) identifies (Alexithymia) or the difficulty in the ability to express feelings as a disorder in emotional and cognitive functions, and it is characterized by a difficulty in describing the person's feelings or failure to recognize them (Gil, et all, 2009), and there existed a deficiency in their social skills and a lack in their social and emotional efficiency (Gilbert, et all, 2014). Alexithymia has many negative effects on psychological health and the behaviors it imposes on the individual that may be inconsistent with his values and habits as a kind of psychological pain (Grégoire, et al, 2005). This fact was referred to in (Gresh ,2017)which states that the thorough and objective description of psychological pain is challenged by many difficulties arising from the interrelationships between sensory feeling, cognitive interpretation and evaluation, and the different meanings that our emotions add to the feeling of pain. The concept of psychological pain is used to describe the general psychological disorders of the individual such as mood disorders, anxiety and perceived stresses (Hale, 2012). Females show high levels of psychological pain compared to males.

The results of (Harrison, Barrow, \& Creed, 1998; Hashem, \&Alghwiri, 2018; Juma'a, \& Farhan,2015; Keogh, \& Holdcroft,2002) highlighted that females suffer from high levels of depression and psychological pain compared to males, while a study (Mazloom, 2017) indicated that the level of psychological pain among faculty members was very high, and there are differences in the level of psychological pain in favor of males. Study (Meerwijk, Ford, \& Weiss, 2015) indicated that there are no significant differences between males and females on the scale and dimensions of Alexithymia. The study (Mikolajczak, \& Luminet, 2006) showed the absence of differences in both Alexithymia and psychological pain that can be attributed to specialization. 
A coherence is observed to a large extent in the association of Alexithymia with psychological pain, where several studies have found a positive statistically significant correlation between Alexithymia and psychological pain (Mikolajczak, \&Luminet,2006; Mutair, 2009; Myers, \& Derakshan, 2015), whereas (Pandey, Saxena, \& Dubey, 2011)showed that there was a strong correlation between fear of happiness, empathy and Alexithymia. The study results of (Rainville, 2002) showed the existence of direct correlation between emotional repression and Alexithymia, whereas study (Shaheen, 2013) showed a direct statistically significant correlation between depressive symptoms and alexithymia among university students.

\section{Statement of the Problem}

The study lies in exposing the relationship between Alexithymia and psychological pain among Palestinian university students. University student's is an important category in the society, it was necessary to pay attention to them, especially in regards to their emotions, as those who have difficulty in expressing their feelings and suffer from psychological and emotional stresses, can be more isolated and less effective in the society. Therefore, such individuals are unable to recognize, understand and express their feelings, and had social and health effects; and suffer from anxiety, depression and a sense of weakness.

\section{Hypotheses}

The study proposed the following hypotheses:

1. There are no statistical significant differences at $\alpha \leq 0.05$ in Alexithymia among the Palestinian university students according to gender and college.

2. There are no statistical significant differences at $\alpha \leq 0.05$ in psychological pain among the Palestinian university students according to gender and college.

3. There are no statistical significant correlation at $\alpha \leq 0.05$ between Alexithymia and psychological pain among Palestinian university students.

\section{Terminology}

1. Alexithymia: the (Simha-Alpern, 2007) defines Alexithymia as "a personality trait that indicates the apparent inability to express feelings, and it includes several components represented in the difficulty of expressing and showing feelings to others and the outward oriented thinking.

2. Psychological pain: the study (Taylor,1992)defines psychological pain as "unpleasant feelings that result from a negative self-assessment and a feeling of inferiority and disability, and that this negative self-assessment may be the result of a person's loss or something or a failure to accomplish things that are closely related to the individual's psychological needs.

\section{Methods}

\section{Approach}

The study used a correlational descriptive approach using a questionnaire, appropriate to the exploratory nature of the research.

\section{Population and Sampling}

The target population consists of Palestinian university students in the West Bank during 2019, which includes 21000 students of Hebron and Al-Quds (9000 and 12000 students respectively). The sample composed of five hundred students randomly selected, due to gender.

\section{Instrumentation}

The Psychological Pain Scale (Mazloom, 2017) was used, which included (30) items, and the second scale was the Toronto Alexithymia Scale (TAS-20) prepared by (Tuminaro, D., \& Pallone, 2003) and used in the study of(Verrocchio, et all, 2016), which consisted of (20) items. Participants were approached in two universities and were asked to complete the questionnaire. The sampling survey instrument sought socio-economic background information about participants' mainly gender, and college.

\section{Instrument Validity}

Validation of the instrument proceeded in two distinct phases. The initial stage involved a group of referees and expert arbitrators who provided comments on the data collection instrument. The second stage involved a pilot study ( $\mathrm{N}=40)$ 108 
to validate the survey using exploratory factor analysis. Factor loading for all items exceeded 0.70 ( 0.73 to 0.84$)$, which implied that the items were suitable to measure each item of Alexithymia and the Psychological Pain among the Palestinian university students.

\section{Instrument Reliability}

The reliability was tested using Cronbach's Alpha Formula, in order to determine the reliability and consistency of the survey. The results of Cronbach's Alpha for the survey instruments (Alexithymia and the Psychological Pain)were 0.94 and 0.91 , respectively, which indicates excellent reliability and consistency.

\section{Data Analysis}

The questionnaire items were rated on a $1-5$ Likert scale ( $1=$ strongly disagree to $5=$ strongly agree). The highest score indicated a highly level of alexithymia and the Psychological Pain among the university students. Descriptive statistics gauged level of Alexithymia and the Psychological Pain among the sampled population using the following key: 2.33 and less indicated a low level, 2.34-3.67 indicated an average level and 3.68 and above indicated a high level of Alexithymia and the Psychological Pain. The following statistical techniques were measured Regression, T. test, Pearson correlation, Cronbach's Alpha, and Factor Analysis using SPSS.

\section{Data Analysis}

The findings of the study showed that there is a positive correlation between alexithymia and psychological pain Rvalue was $(0.28, \mathrm{P}=0.04)$, this is to say, the higher the alexithymia level, the greater the degree of psychological pain is, and vice versa.

Moreover, the results showed that there are significant the differences in the alexithymia level among the sampled population according to the university, that favored Hebron University students (M 3.38, SD 0.61) compared to (M 3.24, SD 0.65) for Al-Quds University students, $\mathrm{T}$. test value was $(2.50, \mathrm{P}=0.01)$. Furthermore, differences were found in the alexithymia level among the sampled students according to the gender, that favored the males(M 3.65, SD 0.28) compared to (M 3.47, SD 0.27) for the females, T. test value was (7.14, $\mathrm{P}=0.00)$. Additionally, differences were found in the alexithymia level among the sampled students according to the college, the differences were in favor of scientific colleges (M 3.61, SD 0.30) compared to (M 3.50, SD 0.27) for humanities colleges, $\mathrm{T}$. test value was (4.11, $\mathrm{P}=0.00)$. Finally, the findings indicated that there are no statistical significant differences in the level of psychological pain among the Palestinian university students due to the study independent variables that are, the university, gender, and the college.

\section{Discussion and Recommendations}

The findings of the study indicated a positive relationship between alexithymia and psychological pain; the higher the level of alexithymia, the greater the degree of psychological pain is, and vice versa. This result is consistent with both studies (Mikolajczak, \&Luminet, 2006; Mutair,2009; Pandey, Saxena, \& Dubey, 2011; Rainville, 2002) and this reflects the strong relationship between Alexithymia and psychological pain, because of their impact on each other.

Hebron University students scored a higher level of Alexithymia than Al-Quds University students. It's to be noted that the nature of Hebron community, where the people are restricted by conservative customs and traditions more than other cities, may limit the people's expression of their feelings towards others, so others prefers to keep those feelings rather than express them explicitly in front of himself and others. On the other hand, many students who join Al-Quds University come from different cities compared to Hebron University. Males students scored a higher level of Alexithymia than, these results disagreed with the results of (Meerwijk, Ford, \& Weiss, 2015; Mikolajczak, \& Luminet, 2006). This may reflect the nature of male or patriarchal societies, which restrict the disclosure of feelings towards others, as it may be interpreted as weakness. Scientific college students scored a higher level of alexithymia than humanities students, these results disagreed with the results of (Mikolajczak, \& Luminet, 2006) which confirmed the absence of differences in the level of specialization or college, and this may be attributed to the lack of interest for students of scientific colleges in poetry, prose and narrative, unlike humanities students, who indulge in literary and poetic vocabulary, which may contribute to their ability to express their feelings towards others.

Finally, no differences found in the level of psychological pain among the Palestinian university students due to the study independent variables that are, the university, gender, and the college. This is a natural and rational result because the Palestinian society lives under the Israeli occupation, especially the students who expect an unknown future of economic, political and service conditions, so all students live similar conditions to some extent. These results disagreed with the study of (Juma'a, \& Farhan, 2015; Keogh, \& Holdcroft, 2002) which indicated that there were 
statistically significant differences for the level of psychological pain and in favor of females, and the study of (Mazloom, 2017)which confirmed the presence of higher psychological pain in males more than females. The above findings confirm the value of alexithymia in increasing the psychological pain among the Palestinian university students, and recommend:

1. Conducting experimental studies to reduce the side effects of alexithymia, in order to avoid reaching an unjustified disorder.

2. A comparative study of alexithymia and psychological pain between other Palestinian universities should be stimulated.

3. Further research is essential in the area of alexithymia and psychological pain using the qualitative research design.

\section{Conclusion}

The existence of a positive correlation between Alexithymia and psychological pain, and that Alexithymia is associated more than the psychological pain among the sampled population, which contributed to the high level of psychological pain among the students, especially the males enrolled at the scientific colleges.

\section{References}

Baum, A., \& Grunberg, N. (1991). Gender, stress, and health. Health Psychology, 10(2), 80.

Besharat, M., Rostami, R., Pourhossein, R., \&Mirzamani, M. (2006). Assessing reliability and validity of Farsi version of the Toronto alexithymia scale-20 in a sample of opioid substance use disordered patients.

Brahmiya, J. (2016). Psychological pain among cancer patients: A field study. EL Bahith Journal in Social Sciences and Humanities, 8 (27), 309-317.

Eastabrook, J. (2008). Assessment of adolescent alexithymia: Examining the ability of the TAS-20 to measure alexithymia in samples of community and clinical adolescents. Unpublished doctoral dissertation, Trent University (Canada).

Eid, P., \& Boucher, S. (2012). Alexithymia and dyadic adjustment in intimate relationships: Analyses using the actor partner interdependence model. Journal of Social and Clinical Psychology, 31(10), 1095-1111.

Gil, F., Ridout, N., Kessler, H., Neuffer, M., Schoechlin, C., Traue, H, \& Nickel, M. (2009). Facial emotion recognition and alexithymia in adults with somatoform disorders. Depression \& Anxiety, 25(11), 26 - 33.

Gilbert, P., McEwan, K., Catarino, F., Baião, R., \&Palmeira, L. (2014). Fears of happiness and compassion in relationship with depression, alexithymia, and attachment security in a depressed sample. British Journal of Clinical Psychology, 53(2), 228-244.

Grégoire Zimmermann, Jérôme Rossier, Franz Meyer de Stadelhofen, François Gaillard.(2005). Alexithymia Assessment and Relations with Dimensions of Personality. European Journal of Psychological Assessment, 21(1), 23-33.

Gresh , Iman .(2017). Depressive symptoms and their relationship to Alexithymia and the maladaptive cognitive schemas among university female students, Educational and Psychological Studies,Zagazig University, 1(96), 141- 229.

Hale, K. (2012). Validity of the Toronto Alexithymia Scale (TAS-20) in an inpatient population. Unpublished doctoral dissertation, College of Education, The Florida State University.

Harrison, J., Barrow, S., \& Creed, F. (1998). Mental health in the north west region of England: associations with deprivation. Social psychiatry and psychiatric epidemiology, 33(3), 124-128.

Hashem, I., \&Alghwiri, A. (2018). The relationship between Alexithymia and obesity among females in Jordan, AnNajah University Journal for Research(Humanities), 32(1), 197-220.

Juma'a, A., \& Farhan, A. (2015). The level of psychological pain among the college members at the University of Anbar. Journal of the University of Anbar for Humanities, 1(2), 407-440.

Keogh, E., \& Holdcroft, A. (2002). Sex differences in pain: Evolutionary links to facial pain expression. Behavioral and Brain Sciences, 25(4), 465-465.

Mazloom, M. (2017). Emotional regulation and its relationship with Alexithymia among a sample of university students: Psychometric-clinical study ", Arab Studies in Education and Psychology, Arab Education Association, 82 (5), 143 - 212.

Meerwijk, E., Ford, J., \& Weiss, S. (2015). Resting-state EEG delta power is associated with psychological pain in adults with a history of depression. Biological psychology, 1(105), 106-114.

Mikolajczak, M., \&Luminet, O. (2006). Is alexithymia affected by situational stress or is it a stable trait related to emotion regulation? Personality and Individual Differences, 1(40), 1399-1408. 
Mutair, H. (2009). Alexithymia and its relationship to anxiety among a sample of blind teenagers. Unpublished master thesis, the Institute for Higher Studies on Childhood, Ain Shams University.

Myers, L., \&Derakshan, N. (2015). The relationship between two types of impaired emotion processing: repressive coping and alexithymia. Frontiers in Psychology, 1(6), 809-824.

Pandey, R., Saxena, P., \& Dubey, A. (2011). Emotion regulation difficulties in alexithymia and mental health. Europe's Journal of Psychology, 7(4), 604-623.

Rainville, P. (2002). Brain mechanisms of pain affect and pain modulation. Current opinion in neurobiology, 12(2), 195-204.

Shaheen, H. (2013). Alexithymia and satisfaction with Life among a sample of University students. Journal of Faculty of Education at Benha University. 1(96), 81-112.

Sherbiny, S. (2012). Impulsivity, Alexithymia and psychological distress among a sample of students from the Faculty of Education at El-Arish University. The Egyptian Journal of Psychological Studies, 22(76), 47-108.

Simha-Alpern, A. (2007). "I finally have words!" Integrating a psychodynamic psychotherapeutic approach with principles of emotional intelligence training in treating trauma survivors. Journal of Psychotherapy Integration, 17(4), 293.

Taylor, G. (1992). 'The alexithymia construct: conceptualization, validation, and relationship with basic dimensions of personality', Paper presented at the International Workshop on Alexithymia, 4th National Congress of the Italian Society of Medical Psychology, University of Pavia, Italy, 9 October 1992.

Tuminaro, D., \& Pallone, N. (2003). Alexithymia, verbal intellectual deficit, and neurological dysfunction in relation to risk-taking behavior. Current Psychology, 22(2), 175-184.

Verrocchio, M., Carrozzino, D., Marchetti, D., Andreasson, K., Fulcheri, M., \&Bech, P. (2016). Mental pain and suicide: a systematic review of the literature. Frontiers in psychiatry, 7(108). 17-30.

\section{About the Authors:}

Omar Taleb Rimawi, Associate Professor, Department of Psychology, Faculty of Educational Sciences, Al-Quds University, Jerusalem- Abu Dies, Palestine. Email: orimawi@staff.alquds.eduhttps://orcid.org/0000-00029376-3917

Ibrahim Suleiman Al-Masri, Assistant Professor, Department of Psychology, Faculty of Education, Hebron University. Email: masrii@hebron.edu 